\title{
Líquido sinovial da articulação femuropatelar após desmotomia patelar medial experimental em eqüinos
}

\author{
Evaluation of the synovial fluid of the femuropatellar joint after experimental medial patellar \\ desmotomy in horses
}

\author{
Edivaldo Aparecido Nunes Martins ${ }^{\mathrm{I}}$ Luís Cláudio Lopes Correia da Silva ${ }^{\mathrm{II}}$ \\ Raquel Yvonne Arantes Baccarin ${ }^{\text {II }}$
}

\section{RESUMO}

A desmotomia patelar medial (DPM) é comumente realizada para o tratamento da fixação dorsal da patela (FDP). $E$ É fécil execução e na maioria dos casos seus resultados são imediatos. Porém, alterações articulares após a DPM têm sido freqüentemente descritas na literatura. O objetivo deste trabalho é descrever as possíveis alterações no líquido sinovial da articulação femuropatelar após desmotomia patelar medial experimental, em eqüinos mantidos em repouso por 120 dias. Foram utilizados oito eqüinos hígidos, adultos, que não apresentaram histórico de lesões no joelho, e que não demonstraram claudicação após exame físico ou teste de flexão dos membros pélvicos. A desmotomia patelar medial foi realizada no membro pélvico direito de cada cavalo. O líquido sinovial foi obtido através de artrocentese durante o período pré-operatório e seqüencialmente no período pós-operatório (po) nos dias 15, 30,60, 90 e 120, sendo avaliado quanto à coloração, viscosidade, proteína total, e contagem total de células nucleadas e contagem diferencial dos leucócitos. A única alteração significativa no líquido sinovial de cavalos submetidos a desmotomia patelar medial e mantidos em repouso por 120 dias foi a alteração da viscosidade no $30^{\circ}$ dia po.

Palavras-chave: liquido sinovial, eqüinos, fixação dorsal da patela, articulação femuropatelar, joelho.

\section{ABSTRACT}

Medial patellar desmotomy (MPD) is a common treatment for upward fixation of the patella (UFP). It is easy to perform, and in most cases results are immediate. However, joint changes after MPD have been described. The purpose of this study is to use synovial fluid evaluate the effects of MPD in horses subjected to restricted exercis in the first 120 days postoperatively. Eight sounds adult horses, weighing from 350 to $480 \mathrm{~kg}$, were used in the study. The selected animals had no history of lesions in the femuropatellar joint and did not demonstrate lameness on physical examination or after hind limb flexion tests. Right medial patellar desmotomy was performed on each horse. The synovial fluid was obtained by arthrocentesis during the selection phase and after surgery on days 15, 30, 60, 90 and 120. Synovial fluid color, viscosity, total protein, and nucleated cell count and diferential leukocyte count was analysed. The poor viscosity on day 30 was the highest significative change from synovial fluid on the horses subject to medial patelar desmotomy and maintened in rest for 120 days.

Key words: synovial fluid, equine, upward fixation of the patella, femuropatellar joint, stifle.

\section{INTRODUÇÃO}

A articulação fêmuro-tíbio-patelar (joelho) é a maior e mais complexa articulação do cavalo, e lesões em uma área podem freqüentemente envolver ou incapacitar outras estruturas estabilizadas, tornando difícil o diagnóstico ou tratamento e, não raramente, comprometendo o prognóstico (LATIMER et al., 2000).

O conhecimento anatomofisiológico do joelho possibilita uma melhor compreensão das particularidades dessa articulação e dos mecanismos envolvidos nas diferentes afecções. $\mathrm{Na}$ descrição de REEVES et al. (1991), a articulação fêmuro-tíbio-patelar (joelho) é formada por três compartimentos, a articulação femuropatelar e as femurotibiais medial e lateral. Em aproximadamente $65 \%$ dos cavalos, as articulações femuropatelar e femurotibial medial se

'Departamento de Cirurgia Veterinária, Faculdade de Medicina Veterinária e Zootecnia (FMVZ), Universidade de São Paulo (USP), São Paulo, Brasil. Endereço para correspondência: Rua Erasmo de Souza Ribeiro, n. 169, 13735-220, Mococa, SP, Brasil. E-mail: eanunes@terra.com.br.

"Departamento de Clínica Médica, FMVZ, USP, São Paulo, Brasil. 
comunicam. Aproximadamente $17 \%$ a $20 \%$ das articulações femuropatelar podem comunicar simultaneamente com ambas articulações femurotibiais. A ausência de comunicação entre as articulações femuropatelar e ambas femurotibiais ocorrem em 17\% dos cavalos. Segundo VACEK et al., (1992) a articulação femurotibial lateral comunica com a articulação femuropatelar exclusivamente em apenas $3 \%$ dos cavalos. A comunicação entre as duas articulações femurotibiais não existe em cavalos normais.

A fixação dorsal da patela (FDP) é uma das causas freqüentes de claudicação em eqüinos e também em ruminantes, caracterizada clinicamente por hiperextensão de um ou de ambos os membros pélvicos, resultante do aprisionamento temporário ou permanente da patela na tróclea medial do fêmur (STASHAK, 2002; JANSSON, 1996). Freqüentemente é denominada de maneira errônea como luxação de patela, apesar de esta afecção ocorrer, mas com manifestação clínica distinta (JANSSON, 1996).

A técnica cirúrgica de desmotomia patelar medial (DPM) é indicada com freqüência elevada para o tratamento da FDP, apesar de a literatura especializada reportar a ocorrência de fragmentação osteocondral na parte distal da patela (AUER, 1999; GIBSON et al., 1989; JANSSON, 1996; MCILWRAITH,1990; SQUIRE et al., 1990), fibrilação da cartilagem articular ou destacamento (GIBSON et al., 1989) e proliferação óssea na inserção patelar do ligamento patelar intermédio (AUER, 1999; GIBSON et al., 1989; JANSSON, 1996; SQUIRE et al., 1990), chegando a ocorrer fraturas patelares nos casos mais graves (RILEY \& YOVICH, 1991).

Dentre as técnicas utilizadas para avaliação do joelho, o exame do líquido sinovial pode auxiliar no diagnóstico de infecção ou determinar o grau de inflamação em casos de traumatismo, lesões do tecido mole articular, ou doenças ortopédicas do desenvolvimento. As alterações do líquido sinovial podem indicar a melhor terapia a ser empregada ou avaliar sua eficácia (MCILWRAITH \& TROTTER, 1996).

O líquido sinovial é um dialisado do plasma viscoso, produzido pela membrana sinovial, com função de lubrificação, nutrição, auxiliando no suporte mecânico e na absorção de impacto. Ele é livre de material floculento ou fragmentos, possui coloração de clara à palha amarelada, e contém hialuronato, eletrólitos, glicose, proteínas e enzimas (KORENEK et al., 1992). O número total de leucócitos em articulações normais é menor do que 1.000 células $\mu \mathrm{L}^{-1}$. Predominam células mononucleares e linfócitos (90\%), com número de neutrófilos menor que $10 \%$ do total de leucócitos (LATIMER et al., 2000). O líquido sinovial normal contém aproximadamente $30 \%$ do valor da proteína plasmática (CURTISS, 1964), sendo o conteúdo protéico normalmente menor que $2,5 \mathrm{~g} \mathrm{dL}^{-1}$.

O objetivo deste trabalho é descrever as possíveis alterações no líquido sinovial da articulação femuropatelar após desmotomia patelar medial experimental, em eqüinos mantidos em repouso por 120 dias.

\section{MATERIAL E MÉTODOS}

Foram utilizados oito eqüinos, adultos, de diferentes raças, seis machos e duas fêmeas, com peso variando entre 350 e $480 \mathrm{~kg}$. Todos os animais foram submetidos a vermifugação $0^{\mathrm{a}}$ e casqueamento, antes do início do experimento. Foram escolhidos os animais que não apresentaram histórico de lesões articulares no joelho e que não demonstraram claudicação após exame físico, incluindo teste de flexão dos membros pélvicos.

A desmotomia patelar medial foi realizada no membro pélvico direito de cada cavalo. A sedação e a analgesia foram obtidas através da associação de romifidina $1 \%$, na dose de $0,08 \mathrm{mg} \mathrm{kg}^{-1}$, iv, e butorfanol ${ }^{\mathrm{c}}$, na dose de $0,04 \mathrm{mg} \mathrm{kg}^{-1}$, iv. Para anestesia local do ligamento patelar medial, fez-se bloqueio infiltrativo subcutâneo com cloridrato de lidocaína $2 \% \mathrm{~d}$ em volume variável entre $10 \mathrm{a} 15 \mathrm{ml}$.

A incisão cutânea foi realizada no sentido próximo-distal, sobre o terço médio do ligamento tíbio patelar medial, medindo aproximadamente $3 \mathrm{~cm}$ de extensão. Após individualização do ligamento tíbio patelar medial, realizou-se a sua secção com bisturi, certificando-se que todas as suas fibras haviam sido seccionadas. A sutura de pele foi procedida com fio de náilon n.0, em padrão simples interrompido.

Ao término do procedimento cirúrgico, foi instituída terapia antimicrobiana com penicilina benzatina, na dose de $20.000 \mathrm{UI} \mathrm{kg}^{-1}$, im a cada $48 \mathrm{~h}$, perfazendo três aplicações. Como analgésico e antiinflamatório, administrou-se fenilbutazona ${ }^{\mathrm{e}}$, na dose de $2,2 \mathrm{mg} \mathrm{kg}^{-1}$, iv, a cada $12 \mathrm{~h}$, durante três dias.

Foi realizado curativo local duas vezes ao dia até a retirada dos pontos no décimo dia pósoperatório (po). Durante o período experimental, os animais permaneceram alojados em baias de $12 \mathrm{~m}^{2}(3 \times 4)$ e receberam como alimentação concentrado comercial e feno de "coast cross".

O líquido sinovial da articulação femuropatelar direita foi obtido através de artrocentese no período pré-operatório e seqüencialmente no 
período pós-operatório, nos dias 15, 30, 60, 90 e 120 . Após tricotomia local e antissepsia com iodopovidona e álcool $70 \%$, uma agulha $40 \mathrm{X} 12$ foi inserida no espaço entre a face lateral da patela e a tróclea femoral lateral, seguindo técnica descrita por HENDRICKSON \& NIXON (1992). O líquido foi coletado em frasco estéril contendo anticoagulante EDTA sódico a 10\%.

O líquido sinovial foi avaliado quanto à coloração, sendo classificado como amarelo claro, amarelo ouro e vermelho; e, quanto ao aspecto, como límpido, semiturvo e turvo, recebendo escores de 0 a 2 para cada característica analisada.

A viscosidade foi analisada colocando-se uma gota de líquido sinovial no polegar e tocando-a com o indicador, e, após isso, separando-se os dedos para verificação da extensão do fio formado antes de se romper. A viscosidade foi graduada em boa ( 0 - fio com tamanho de 2,5 a 5cm); regular (1- fio com tamanho menor que 2,5 cm); e ruim (2 - não há formação de fio).

Para as dosagens de proteína total, foi utilizado o sobrenadante retirado após centrifugação da amostra destinada à contagem total de células nucleadas. As dosagens da proteína total foram realizadas por refratometria. Para a contagem total de células nucleadas, amostras contendo $1,0 \mathrm{~mL}$ foram centrifugadas durante 10 minutos a $2.000 \mathrm{rpm}$ e o sedimento ressuspendido em 1,0mL de PBS (solução tampão de fosfato), realizando-se a contagem em câmara de Neubauer. Em seguida, foram confeccionados os esfregaços, corados com Metanol-May GrunwaldGiemsa, para a contagem diferencial dos leucócitos.

Os dados foram avaliados segundo a normalidade pelo teste de Kolmogorov-Smirnov; em seguida, utilizou-se modelo de análise de variância para verificar o efeito de momentos. O contraste entre médias foi feito pela dms do teste de Tukey a nível de $5 \%$ de probabilidade (SAMPAIO, 1998), para o processamento dos dados. Para os dados não paramétricos, utilizou-se o teste de Kruskal-Walis.

\section{RESULTADOS}

Das 48 punções articulares, foi possível obter líquido sinovial em 40 (83,33\%); dessas, em 28 (70\%) ocorreu contaminação com sangue. Em três punções, a colheita foi improdutiva e, em cinco, o volume foi insuficiente para todas as análises. Devido à ocorrência de contaminação em 70\% das colheitas, essas amostras apresentaram-se com coloração vermelha, porém de aspecto límpido.

Houve piora significativa na viscosidade do líquido sinovial no $30^{\circ}$ dia po (Figura 1). A viscosidade foi classificada como boa para todos os animais no exame controle. No $15^{\circ}$ dia po, a viscosidade foi classificada como boa para quatro animais e regular para quatro. No $30^{\circ}$ dia po, foi classificada como boa para dois animais, regular para cinco e ruim para um animal. No $60^{\circ}$ dia po, foi classificada como boa para três animais, regular para três e a colheita foi improdutiva em dois animais, impossibilitando a realização da prova da viscosidade. No $90^{\circ}$ dia po, foi classificada como boa para três animais e regular para cinco. No $120^{\circ}$ dia po, foi classificada como boa para três animais, regular para quatro e a colheita foi improdutiva em um animal.

A proteína do líquido sinovial apresentou discreto aumento no $15^{\circ}$ e no $30^{\circ}$ dia po, diminuindo gradativamente até o $120^{\circ}$ dia po. Os leucócitos aumentaram a partir do 15을 dia p.o., mantendo-se até o $90^{\circ}$ dia po, e retornando no $120^{\circ}$ dia po aos valores próximos do exame controle (Tabela 1).

\section{DISCUSSÃo}

Dentre as três articulações do joelho, a articulação femuropatelar foi escolhida para artrocentese devido ao ligamento tibiopatelar medial ser uma das estruturas responsáveis em manter o alinhamento da patela no sulco troclear e estar próximo à cápsula dessa articulação, além de os estudos retrospectivos e experimentais indicarem a articulação femuropatelar como local de ocorrência de lesões após a desmotomia patelar medial (AUER, 1999; GIBSON et al., 1989; JANSSON, 1996; MCILWRAITH, 1990; RILEY \& YOVICH, 1991; SQUIRE et al., 1990). Devido às características anatômicas, o líquido sinovial da articulação femuropatelar pode apresentar as mesmas características daquele encontrado nas articulações femurotibiais, devendo ser considerado durante análise do líquido sinovial.

Como a viscosidade do líquido sinovial está diretamente relacionada ao conteúdo de hialuronato (SUGIUCHI et al., 2005; TULAMO et al., 1994; TULAMO et al., 1996), a diminuição observada no $30^{\circ}$ po é sugestiva de trauma articular causado pela desmotomia patelar medial. Segundo SUGIUCHI et al. (2005), na presença de inflamação, as enzimas no líquido sinovial quebram a molécula de hialuronato, o volume de líquido sinovial aumenta e a viscosidade diminuiu. Os animais que não apresentaram alterações na viscosidade foram os mesmos que mantiveram a contagem de leucócitos abaixo de 250 células $\mathrm{mm}^{-1}$, portanto, não apresentaram inflamação.

Ainda referente à contagem total de leucócitos no líquido sinovial, os valores médios permaneceram dentro dos parâmetros normais, ou seja,

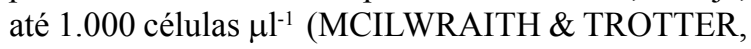
1996). Este fato foi reforçado pela análise citológica que mostrou predomínio de células mononucleares com 


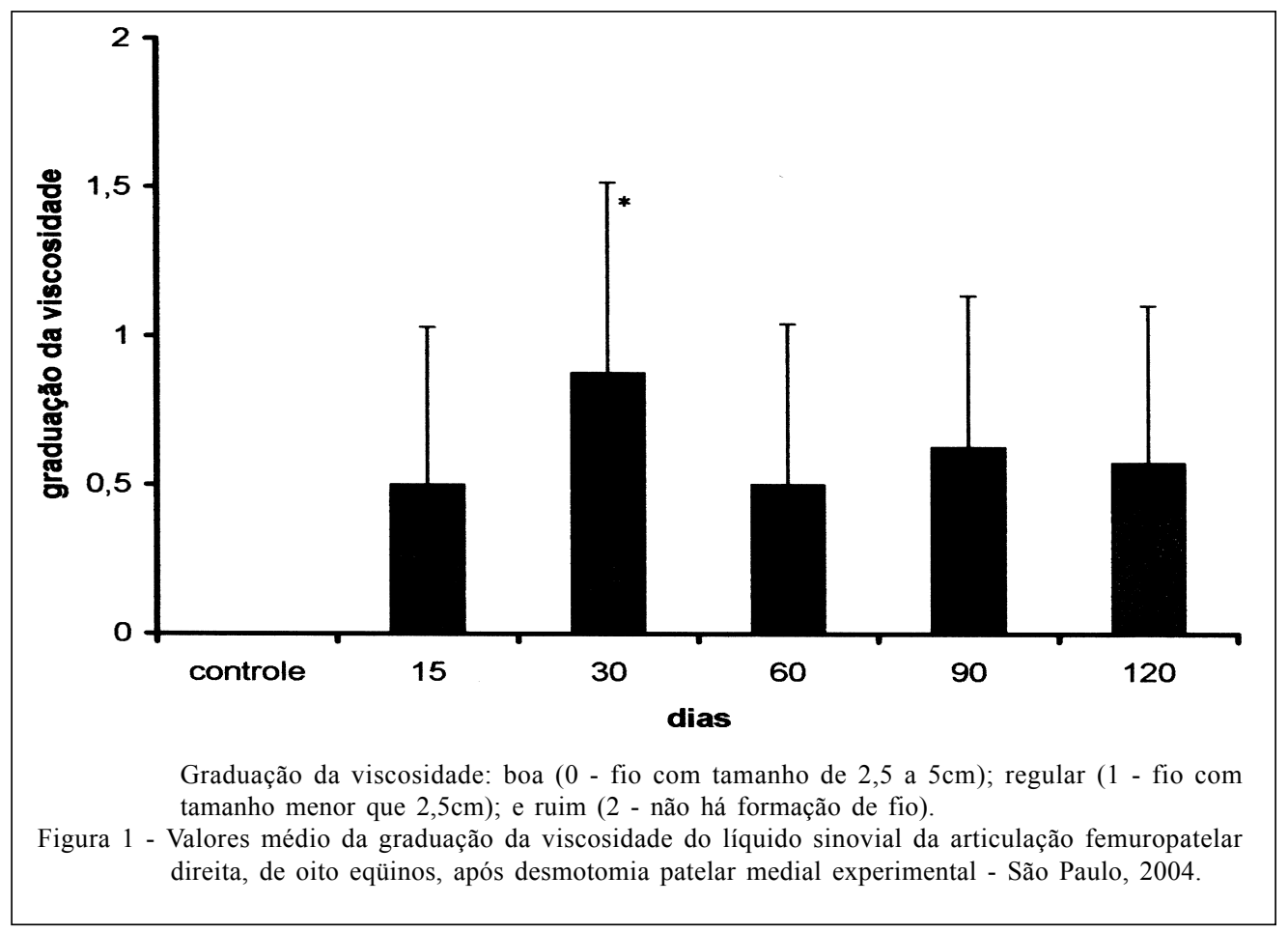

raros neutrófilos, compatível ao classificado como normal por LATIMER et al. (2000). No 15 dia po o desvio padrão encontrado foi decorrente da contagem elevada de leucócitos no líquido sinovial de um único animal. Como o aumento dos leucócitos entre $1.000 \mathrm{a}$ 5000 células $\mu \mathrm{l}^{-1}$ está normalmente associado a osteocondrose, trauma leve, ou efusão sinovial idiopática (MCILWRAITH \& TROTTER, 1996), podese atribuir o aumento dos leucócitos observado no exame do 15 o dia po ao trauma cirúrgico ou à instabilidade articular causada pela secção do ligamento tíbio patelar medial.

No decorrer do experimento, a proteína do líquido sinovial apresentou-se dentro dos valores normais de referência, apesar de um aumento discreto no $15^{\circ}$ e no $30^{\circ}$ dia po, não ultrapassando $2,5 \mathrm{~g} \mathrm{dl}^{-1}$, que, segundo LATIMER et al. (2000), é compatível com a normalidade. Logo, apesar da diminuição de viscosidade do líquido sinovial, não foram observadas alterações na concentração de proteína, não sugerindo lesões cartilagíneas ou na membrana sinovial, que, segundo NILSSON \& PERSSON (1973), estariam correlacionadas com alterações no conteúdo protéico.

Como as hemácias não são consideradas constituintes normais do líquido sinovial (STASHAK, 2002), conclui-se que houve contaminação durante a artrocentese. HENDRICKSON \& NIXON (1992) obtiveram líquido sinovial em $30(93,75 \%)$ de 32 artrocenteses parapatelares, e em $18(60 \%)$ amostras houve contaminação com sangue. Quando comparado à artrocentese entre os ligamentos tibiopatelares, acredita-se que a vantagem da artrocentese parapatelar é a obtenção de fluído sinovial de uma articulação sem distensão, com diminuição dos riscos de laceração da cartilagem articular com a movimentação do animal.

\section{CONCLUSÃO}

Nas condições deste experimento, pode-se concluir que a piora da viscosidade do líquido sinovial

Tabela 1 - Valores médios e desvio padrão $( \pm \mathrm{DP})$ da concentração de proteína total $\left(\mathrm{g} \mathrm{dl}^{-1}\right)$ e da contagem de leucócitos $\left(\right.$ células $\left.\mu \mathrm{L}^{-1}\right)$ do líquido sinovial das articulações femuropatelares direitas, após desmotomia patelar medial experimental - São Paulo, 2004.

\begin{tabular}{llllll}
\hline Constituinte & Controle & dia 15 & dia 30 & dia 60 & dia 90 \\
\hline Proteína total & $1,52^{\mathrm{a}} \pm 1,1$ & $2,5^{\mathrm{a}} \pm 1,0$ & $2,33^{\mathrm{a}} \pm 0,7$ & $1,95^{\mathrm{a}} \pm 0,9$ & $1,88^{\mathrm{a}} \pm 0,9$ \\
Contagem de leucócitos & $216,67^{\mathrm{a}} \pm 291$ & $587,5^{\mathrm{a}} \pm 599$ & $507,14^{\mathrm{a}} \pm 344$ & $508,33^{\mathrm{a}} \pm 376$ & $400^{\mathrm{a}} \pm 394$ \\
\hline
\end{tabular}

Letras minúsculas distintas na mesma linha diferem significantemente em nível de $\mathrm{P}<0,05$.

Ciência Rural, v.37, n.3, mai-jun, 2007. 
é a única alteração significativa observada em eqüinos submetidos a desmotomia patelar medial e mantidos em repouso por 120 dias.

\section{AGRADECIMENTOS}

À Fundação de Amparo à Pesquisa do Estado de São Paulo (FAPESP) pelo financiamento do projeto.

\section{FONTES DE AQUISIÇÃO}

${ }^{a}$ Eqvalan ${ }^{\circledR}$ Pasta - Merial - Brasil.

${ }^{\mathrm{b}}$ Sedivet $^{\circledR}$ - Boehringer - Brasil.

${ }^{\mathrm{c}}$ Torbugesic ${ }^{\circledR}$ - Fort Dodge Laboratories, Inc., USA.

${ }^{\mathrm{d}}$ Lidison ${ }^{\circledR}$ - Ariston - Brasil.

${ }^{\mathrm{e}}$ Equipalazone ${ }^{\circledR}$ - Marcolab - Brasil.

\section{COMITÊ DE ÉTICA E BIOSSEGURANÇA}

Este trabalho foi aprovado pela Comissão de Bioética da Faculdade de Medicina Veterinária e Zootencia da Universidade de São Paulo, e os estudos foram realizados de acordo com os princípios éticos de experimentação animal. Protocolo no 271/2003.

\section{REFERÊNCIAS}

AUER, J.A. Diseases with physical causes. In: COLAHAN, P.T. et al. Equine medicine and surgery. 5.ed. St Louis: Mosby, 1999. V.2, p.1706-1710.

CURTISS, P.H. Changes produced in the synovial membrane and synovial fluid by disease. Journal of Bone and Joint Surgery, v.46-A, n.4, p.873-888, 1964.

GIBSON, K.T. et al. Production of patellar lesions by medial patellar desmotomy in normal horses. Veterinary Surgery, v.18, n.6, p.466-471, 1989.

HENDRICKSON, D.A.; NIXON, A.J. A lateral approach for synovial fluid aspirattion and joint injection of the femorpatellar joint of the horse. Equine Veterinary Journal, v.24, n.5, p.399-401, 1992.

JANSSON, N. Treatment for upward fixation of the patella in the horse by medial patellar desmotomy: indications and complications. Equine Practice, v.18, n.4, p.24-29, 1996.

KORENEK, N.L. et al. Determination of total protein concentration and viscosity of synovial fluid from the tibiotarsal joints of horses. American Journal Veterinary Research, v.53, n.5, p.781-784, 1992.
LATIMER, F.G. et al. Stifle disease in horses. Compendium Continuing Education Practicing Veterinarian, v.22, n.4, p.381-390, 2000.

MCILWRAITH, C.W. Osteochondral fragmentation of the distal aspect of the patella in horses. Equine Veterinary Journal, v.22, n.3, p.157-163, 1990

MCILWRAITH, C.W.; TROTTER, G.W. Joint disease in the horse. Philadelphia: Saunders, 1996. p.120-164.

NILSSON, G.; PERSSON, L. Changes in the synovial fluid of equine fetlock joints with lesions in the cartilage and joint capsule. Acta Veterinaria Scandinavica, v.44, p.99-107, 1973.

REEVES, M.J. et al. Anatomical and functional communications between the synovial sacs of the equine stifle joint. Equine Veterinary Journal, v.23, n.3, p.215-218, 1991.

RILEY, C.B.; YOVICH, J.V. Fracture of the apex of the patella after medial patelar desmotomy in a horse. Australian Veterinary Journal, v.68, p.37-39, 1991.

SAMPAIO, J.B.M. Estatística aplicada à experimentação animal. Belo Horizonte: Fundação de pesquisa e ensino em Medicina Veterinária e Zootecnia, 1998. 221p.

SQUIRE, K.R.E. et al. Radiographic changes in an equine patella following medial patellar desmotomy. Veterinary Radiology, v.31, n.4, p.208-209, 1990.

STASHAK, T.S. Adam's lameness in horses. 5.ed. Philadelphia: Willians \& Wilkins, 2002. 341p.

SUGIUCHI, H. et al. Measurement of total and differential white blood cell counts in synovial fluid by means of an automated hematology analyzer. J Lab Clin Med, v.146, n.1, p. $36-47,2005$

TULAMO, R-M. et al. Concentration and molecular weight distribution of hyaluronate in synovial fluid from clinically normal horses and horses with diseased joints. American Journal of Veterinary Research, v.55, n.5, p.710-715, 1994.

TULAMO, R-M. et al. Hyaluronate and large molecular weight proteoglycans in synovial fluid from horses with various arthritis. American Journal of Veterinary Research, v.57, n.6, p.932-937, 1996.

VACEK, J.R. et al. Communication between the femoropatellar and medial and lateral femorotibial joints in horses. American Journal of Veterinary Research, v.53, n.8, p.1431-1434, 1992 . 